\title{
WATER SORPTION AND DESSICCATION IN A PORTLAND CEMENT PASTE: POSITRON ANNIHILATION RESULTS
}

\author{
G. Consolati ${ }^{a}$, G. Dotelli ${ }^{b}$ and F. Quasso ${ }^{a}$ \\ ${ }^{a}$ Dipartimento di Fisica and Istituto Nazionale per la Fisica della Materia \\ Politecnico di Milano, 20133 Milan, Italy \\ ${ }^{b}$ Dipartimento di Chimica Industriale ed Ingegneria Chimica "G. Natta" \\ Politecnico di Milano, 20133 Milan, Italy
}

\begin{abstract}
Positron annihilation experiments were carried out on a Portland cement paste one year aged, which was subjected to cycles of dessiccation and subsequent water resaturation, in order to study possible changes of the porosity. Analysis of the annihilation time spectra suggests that drying and rewetting treatments do not induce irreversible modifications in the configuration of the finest gel pores.
\end{abstract}

PACS numbers: 78.70.Bj, 71.60.+z, 81.05.Rm

\section{Introduction}

Although positron annihilation has been revealed as a useful experimental method to get information on porous materials like zeolites [1], silica gels [2], and Vycor glasses [3], it has been seldom applied to the characterization of cement-based materials $[4,5]$. Cements display an open, continuous pore system, as originated by the hydration of the cement powder; this last is a complex process, with many different reactions taking place both in parallel and in series [6]. Since the final mechanical properties of the hardened cementitious materials and their durability strongly depend on the porosity [7], a technique — as positron annihilation able to probe the pore size can be useful to gain insight into the microscopic structure of the material. We recently started an investigation on ordinary Portland cement pastes characterized by various water-to-cement ratios and at different ageing times [8-10], in order to assess the sensitivity of the technique to changes in the smallest (gel) pores.

Cement samples are generally dried to evaluate the specific area by gas sorption of different sorbates (mainly nitrogen or water), or via mercury intrusion porosimetry [11]. However, water removal could give rise to microstructural 
modifications (gel pores shrinkage, collapse, etc.), although in the resaturation of previously dried samples the surface area loss due to the initial drying is reversible.

We addressed this problem using the positron annihilation technique; in this paper we report some preliminary results, obtained on a mature cement paste.

\section{Experimental}

\subsection{Material}

Ordinary Portland cement type I according to UNI standard, as supplied by the producer (Cementirossi Piacenza), was used. The chemical composition in weight percentage was: $\mathrm{SiO}_{2}=20.96, \mathrm{CaO}=61.83, \mathrm{Al}_{2} \mathrm{O}_{3}=4.89, \mathrm{Fe}_{2} \mathrm{O}_{3}=$ $1.76, \mathrm{SO}_{3}=3.18$, and other oxides such as $\mathrm{MgO}, \mathrm{TiO}_{2}, \mathrm{Na}_{2} \mathrm{O}$, and $\mathrm{K}_{2} \mathrm{O}$ in few percents. The average particle diameter was $11.10 \mu \mathrm{m}$ and the surface area $0.72 \mathrm{~m}^{2} / \mathrm{g}$. The paste was prepared by mixing the powder with deionized water in the water-to-cement mass ratio $w / c=0.4$; it was shaped into cylindrical pellets with an average diameter of $20 \mathrm{~mm}$ and $2 \mathrm{~mm}$ thick by moulding them in a properly designed plexiglass container. After pouring the fresh paste, the container was cured at $100 \%$ relative humidity $(\mathrm{RH})$ and laboratory temperature $\left(20^{\circ} \mathrm{C} \pm 2\right)$ for 24 hours, and then the pelletized samples demoulded and aged under the same conditions of RH and temperature.

Measurements were made on a mature paste (one year aged), in order to avoid sensible changes in the microstructure: indeed, the specimen had already reached a sufficiently high degree of hydration. It was subjected twice to a drying-rewetting procedure: (a) oven-dried at $105^{\circ} \mathrm{C}$ until it reached a constant weight; this granted that all the free water was eliminated. (b) Curing at $100 \% \mathrm{RH}$ and/or immersion into deionized water; in this last case, it was wiped before measurement. After each step, the sample was analysed by means of positron spectroscopy. All measurements were performed at room temperature.

\subsection{Positron measurements}

The positron source, $0.3 \mathrm{MBq}$ of ${ }^{22} \mathrm{Na}$, was dried onto two identical kapton (DuPont Co.) foils (thickness $1.08 \mathrm{mg} \cdot \mathrm{cm}^{-2}$ ). Positron spectra were collected through a conventional fast-fast coincidence setup [8]; the resolution of the apparatus was about 220 ps. Each spectrum contained about 10 Mcounts. Deconvolutions were carried out through the computer code $L T$ [12], with a suitable correction for positrons annihilated in the kapton.

\section{Results and discussion}

Annihilation time spectra were analysed into discrete components; their number was 3 or 5 , according to the treatment carried out on the sample. The $\chi^{2}$ always resulted less than 1.1. The results are shown in Table. The two shortest components represent average values of annihilation processes of the positron in the various regions with different electron density present in a porous material and cannot be attributed to single decay modes. Since we are only interested to 
TABLE

Lifetimes and intensities of the positron annihilation spectrum in the investigated Portland cement.

\begin{tabular}{c|c|c|c|c|c|c|c|c|c|c}
\hline \hline $\begin{array}{c}\text { Sample } \\
\text { treatment }\end{array}$ & $\begin{array}{c}\tau_{1} \\
{[\mathrm{~ns}]}\end{array}$ & $\begin{array}{c}I_{1} \\
{[\%]}\end{array}$ & $\begin{array}{c}\tau_{2} \\
{[\mathrm{~ns}]}\end{array}$ & $\begin{array}{c}I_{2} \\
{[\%]}\end{array}$ & $\begin{array}{c}\tau_{3} \\
{[\mathrm{~ns}]}\end{array}$ & $\begin{array}{c}I_{3} \\
{[\%]}\end{array}$ & $\begin{array}{c}\tau_{4} \\
{[\mathrm{~ns}]}\end{array}$ & $\begin{array}{c}I_{4} \\
{[\%]}\end{array}$ & $\begin{array}{c}\tau_{5} \\
{[\mathrm{~ns}]}\end{array}$ & $\begin{array}{c}I_{5} \\
{[\%]}\end{array}$ \\
\hline hydration $^{a}$ & 0.263 & 60 & 0.51 & 30 & 1.71 & 10.3 & - & - & - & - \\
& $(5)$ & $(2)$ & $(2)$ & $(2)$ & $(4)$ & $(5)$ & - & - & - & - \\
wetting $^{b}$ & 0.235 & 28 & 0.42 & 60 & 1.60 & 11.8 & - & - & - & - \\
& $(6)$ & $(2)$ & $(2)$ & $(2)$ & $(4)$ & $(5)$ & - & - & - & - \\
oven-drying $^{c}$ & 0.238 & 42 & 0.43 & 49 & 1.48 & 6.4 & 7.5 & 1.5 & 40 & 1.1 \\
& $(6)$ & $(2)$ & $(2)$ & $(2)$ & $(5)$ & $(4)$ & $(8)$ & $(2)$ & $(4)$ & $(1)$ \\
hydration $^{a}$ & 0.261 & 61 & 0.54 & 29 & 1.77 & 10.3 & - & - & - & - \\
& $(5)$ & $(2)$ & $(2)$ & $(2)$ & $(4)$ & $(5)$ & - & - & - & - \\
wetting $^{b}$ & 0.251 & 55 & 0.51 & 33 & 1.75 & 11.7 & - & - & - & - \\
& $(5)$ & $(2)$ & $(2)$ & $(2)$ & $(4)$ & $(5)$ & - & - & - & - \\
oven-drying $^{c}$ & 0.240 & 42 & 0.45 & 49 & 1.66 & 5.6 & 8.2 & 1.5 & 37 & 1.0 \\
& $(5)$ & $(2)$ & $(2)$ & $(2)$ & $(4)$ & $(4)$ & $(8)$ & $(2)$ & $(4)$ & $(1)$ \\
wetting $^{b}$ & 0.266 & 63 & 0.58 & 26 & 1.87 & 11.1 & - & - & - & - \\
& $(6)$ & $(2)$ & $(2)$ & $(2)$ & $(5)$ & $(5)$ & - & - & - & - \\
\hline
\end{tabular}

${ }^{a}$ Curing at $100 \% \mathrm{RH}$ and room temperature.

${ }^{b}$ Immersion in water for 8 hours.

${ }^{c}$ Drying at $105^{\circ} \mathrm{C}$ for 8 hours.

the longest lifetime components, representing ortho-Ps decays, we will not discuss them further.

The third component can be ascribed to Ps annihilated in the pores containing water. The corresponding intensity can be correlated to the concentration of such pores. The decrease in the intensity following a drying of the sample is in relation to the loss of water (free water) from the pores; correspondingly, two components appear displaying a much longer lifetime, which can be attributed to Ps annihilation in the evacuated gel pores [9]. Since the decay through the "pickoff" process is negligible in the larger cavities, ortho-Ps in the capillary pores mainly annihilates into three photons, which cannot be revealed with proper efficiency by means of our experimental apparatus. For this reason the intensity $I_{3}$ in the spectra corresponding to hydrated samples is higher than the sum of the intensities $I_{3}+I_{4}+I_{5}$ as measured on the dried samples. The two longest lifetime components which result from the deconvolutions of the spectra corresponding to dried samples can be interpreted as the "edges" of a lifetime distribution, which is correlated to the distribution of the pores [9].

The results suggest that the drying procedure does not induce irreversible modifications in the structure of the gel pores: indeed, lifetimes and intensities of 
the longest components of the spectra corresponding to the two subsequent drying treatments are well reproducible. We deduce that the dimensions of the pores as well as their concentration are restored. The reproducibility of the results occurs also when the sample is subjected to hydration, or when it is immersed in water: indeed, intensity $I_{3}$ recovers - after drying — the same value, within the errors, typical of the respective states. This does not mean that the structure of the material is not sensitive to the treatment: for instance, the hydration products are not stable under wetting, but undergo swelling [13], which is compensated after drying. Unfortunately, we cannot monitor such processes, since the correlation between ortho-Ps lifetime and dimensions of the holes is valid only when the pores are evacuated. Our findings can be compared with those of Odler and Köster [14-16], who carried out density, total and bound water, porosity and surface area measurements on native and resaturated samples after drying. They did not find differences in the above quantities, except for surface area values, which were lower in resaturated samples. Since the values of total porosity were almost identical in non-dried (native) and resaturated samples, it can be argued that a change in the pore structure occurs. These modifications should involve pores with radii larger than a few $\mathrm{nm}$, since finest gel pores (ultramicropores) are not affected, according to our results.

\section{Conclusions}

We can conclude that drying does not seem to induce irreversible changes in the structure of the finest gel pores in a cement paste; indeed, ortho-Ps parameters in the time annihilation spectra corresponding to analogous treatments of drying and rewetting, performed on the same sample are well reproducible. Our analysis, when compared with the results by Odler and Köster, add information to their conclusion as far as finest gel pores are concerned. We recall that gel pores are the only pores we can probe with this kind of spectroscopy, whose features unfortunately do not allow us also to investigate the pore size distribution in the presence of free water.

\section{Acknowledgments}

This work has been supported by the Italian Ministry of University and Scientific and Technological Research under the MURST-Cofin99 project.

\section{References}

[1] K.J. Hung, C.C. Huang, D.C. Huang, P.K. Tseng, W.F. Huang, Mater. Sci. Forum 255-257, 299 (1997).

[2] Y. Kobayashi, K. Takeuchi, Mater. Sci. Forum 175-178, 703 (1995).

[3] K. Ciesielski, A.L. Dawidowicz, T. Goworek, B. Jasińska, J. Wawryszczuk, Chem. Phys. Lett. 289, 41 (1998). 
[4] T. Rybka, C. Rybka, T. Goworek, R. Wasiewicz, J. Wawryszczuk, Cem. Concr. Res. 12, 747 (1982).

[5] R. Myllylä, M. Karras, Appl. Phys. 7, 303 (1975).

[6] I. Odler, in: Lea's Chemistry of Cement and Concrete, 4th ed., Ed. P.C. Hewlett, Arnold Publishers, London 1998, p. 241.

[7] B. Marchese, in: Advances in Cement Technology, Ed. S.N. Ghosh, Pergamon Press, Oxford 1983, p. 441.

[8] G. Consolati, G. Dotelli, F. Quasso, Mater. Sci. Eng. A 262, 304 (1999).

[9] G. Consolati, G. Dotelli, F. Quasso, J. Appl. Phys. 86, 4225 (1999).

[10] G. Consolati, G. Dotelli, F. Quasso, Radiat. Phys. Chem. 58, 727 (2000).

[11] J.J. Thomas, H.M. Jennings, A.J. Allen, Concr. Sci. Eng. 1, 45 (1999).

[12] J. Kansy, Nucl. Instrum. Methods Phys. Res. A 374, 235 (1996).

[13] C.D. Lawrence, in Ref. [6], p. 400.

[14] H. Köster, I. Odler, Cem. Concr. Res. 16, 207 (1986).

[15] I. Odler, H. Köster, Cem. Concr. Res. 16, 893 (1986).

[16] I. Odler, H. Köster, Cem. Concr. Res. 21, 975 (1991). 